\title{
Parental neglect of feeding in obese individuals
}

\author{
A review of scientific evidence and its application among Saudi \\ population
}

Mosa A. Shubayr, BDS, MSPH, Khurshid A. Mattoo, BSc, MDS.

\begin{abstract}
واجه البشر سوء التغذية خلال القرن العشرين وِالسمنة في القرن القادم) .

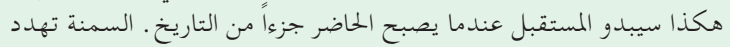

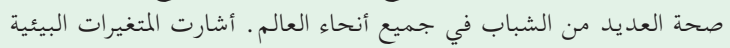

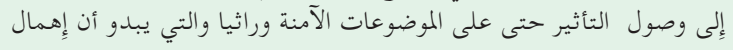

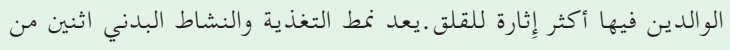

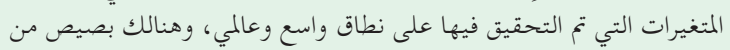

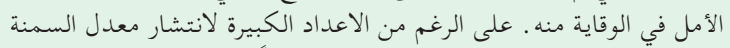

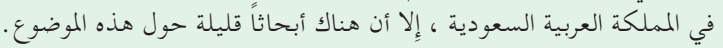

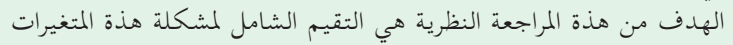

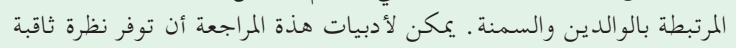

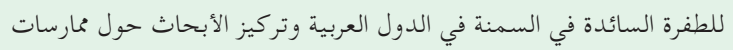

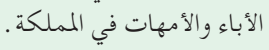

Human beings encountered malnutrition during the twentieth century and obesity in the very next century. This is how the future will look when the present becomes a slice of history. Obesity is threatening the healthy being of many youngsters throughout the world. Environmental influences have indicated to effect even genetically safe subjects among which parental neglect seems to be most alarming. Two extensively and globally investigated variables, the feeding style and the physical activity, provide some hope in its prevention. Despite the high rise of obesity prevalence in Saudi Arabia, there is scant research on these topics. The purpose of this review is to present a comprehensive assessment of these 2-obesity associated parental variables. The composed literature could provide an insight to the dominant surge of obesity in the Arab nations and stimulate research on current parenting practices in the Kingdom.

Keywords: parenting, neglect, feeding style, physical activity

Saudi Med J 2020; Vol. 41 (5): 451-458 doi: $10.15537 /$ smj.2020.5.25049
From the Department of Preventive Dental Sciences (Shubayr) and from the Department of Prosthetic Dental Sciences (Mattoo), College of Dentistry, Jazan University, Jazan, Kingdom of Saudi Arabia.

Address correspondence and reprint request to: $D r$ Khurshid A. Mattoo, Department of Prosthetic Dental Sciences, College of Dentistry, Jazan University, Jazan, Kingdom of Saudi Arabia. E-mail:drkamattoo@rediffmail.com

ORCID ID: https://orcid.org/0000-0003-1191-437X

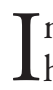
$\mathrm{n}$ the preceding 2 centuries, the medical profession has witnessed unexpected, powerful and pandemic shift in the field of nutritional and its related behavioral disorders. Last century, malnutrition was threatening children's life, this century, overweight and obesity (Ov/ $\mathrm{Ob})$ have become a pandemic clinical condition and a major health burden; the average health care cost of which has been estimated to be between $0.7 \%$ and $2.8 \%$ of country's total health care cost. ${ }^{1}$ The condition instigated from various American states, then with time after crossing Europe has steadily risen in low and middle income countries since $1990 .{ }^{2}$ For low income countries the extent of the problem can be appraised by the fact that in 2017, mean annual health care expenditure was $12 \%$ (for overweight) and 36\% (for obese) more than normal weight individuals. ${ }^{3}$ Historically, health risk associated with obesity was recognized in $1930^{4}$ when life insurance companies determined premiums using body weight data. Children are more vulnerable to develop obesity and their prevalence in the USA has increased more than $5 \%$ between 1976 and 2016. ${ }^{5}$ Obesity has a multifactorial etiological predisposition and is a condition that results due to hereditary (genetic) in between $47 \%-80 \%$ of affected individuals. ${ }^{6}$ Heredity determines child's BMI, ${ }^{6}$ body weight and shape, ${ }^{6}$ location of fat stores ${ }^{7}$ and hormonal influence. ${ }^{8}$ The role of environment can influence both genetically prone and normal individuals. Environmental influences $(30 \%$ to $60 \%)$ on obesity in remaining 
individuals include behavioral (Energy balance related behavior), ${ }^{6}$ cultural, ${ }^{9}$ and psychological factors ${ }^{10}$ (stress, depression, maternal antipathy and neglect and child maltreatment) that are directly or indirectly related to parenting. Outstandingly, parental neglect is a significant environmental factor that has implications on adulthood obesity. ${ }^{11-16}$ Parental neglect is mostly not intentional, but scientific evidence has identified 3 forms of parental neglect associated with obesity: medical, ${ }^{17}$ supervisory, and care neglect. ${ }^{18}$ During the last decade, an alarming rise in obesity prevalence has been reported from countries of the Gulf Cooperation Council (GCC) (Kuwait, Qatar, Saudia Arabia, and Bahrain). As high as $66-75 \%$ of the adult population has been reported to suffer from overweight and obesity in the Kingdom of Saudi Arabia (KSA). ${ }^{19,20}$ While the occurrence of childhood obesity increased from $25 \%$ to $40 \%$ between year 2005 and 2013, adult obesity during the same period has witnessed an increase from $20 \%$ to $60 \%$ in the Kingdom (Centers for disease control and prevention: Adult obesity facts, 2013). There is a severe increase in obesity among adults during the running decade. Because of conservative social determinants in terms of tradition and culture, issues like parental neglect are untouchable due to the lack of awareness among the Saudi population. This literature review was aggregated as ancillary preparation for a comparative study which explored the link between parental neglect in terms of feeding style between normal and overweight/obese subjects. This review is aimed to appraise the scientific community with the scientific evidence that is related to parental neglect (in terms of feeding and body activity) and its possible application in future research on obesity in the KSA. A literature search (2000-2019) was conducted on 7 different medical electronic databases (Pubmed, PsycINFO, Google scholar, Scopus, MEDLINE, Scopus, Proquest). Associated search included use of individual and/or combination of terms such as parental neglect, child maltreatment, obesity/overweight, feeding style, parenting style, physical activity, Saudi Arabia, clinical trial, crosssectional, randomized, placebo controlled, qualitative or quantitative, empirical and survey. Relevant papers were selected after screening of references, titles, keywords, abstracts and full texts by 2 independent reviewers using a prepared piloted form for the review. The primary

Disclosure. Authors have no conflict of interests, and the work was not supported or funded by any drug company. focus was on the variables associated with the predictors of adulthood obesity like parenting, home environment, feeding style, social activity, and child neglect. Due to the lack of research in this field in KSA, we also included gray literature (unpublished thesis, conference papers, government reports) that was outside the traditional commercial or academic publishing. ${ }^{21}$ The final list for this review included 75 full length articles out of which 62 were research articles while the rest included reports, guidelines, thesis, and literature reviews.

Definition. Parental neglect is a socially sensitive issue, especially in middle east countries due to their conservative, traditional and cultural basis and studies in these domains is noticeable by its absence, although neglected dental care, child abuse ${ }^{22}$ and substance abuse (Catha edulis-Khat) ${ }^{23}$ have been reported. The terms child abuse and parent neglect are interrelated to a large extent, but there are cases where parents do not intend to neglect their children. Therefore, parental neglect for the current review is operationally described as a "circumstance wherein parental inaction or inattention results in harm to a child, or a circumstance where the basic needs of the children are not met". Since the issues pertaining to the definition of fatal neglect ${ }^{24}$ is out of the scope of this article, the existing traditional definition of parental neglect has been used. Parental neglect in the context of obesity, is either neglect of care, supervision, and medical attention. ${ }^{17,18}$ Parenting in the current context is defined as providing a nurturing and constructive environment that promotes ideal growth and development in a child or children (Miller-Keane Encyclopedia and Dictionary of Medicine Nursing, and Allied Health).

Parental neglect types identified in obesity. Care neglect. Facets of care identified within a family environment are parental denial of children being obese, mother-child separation, disorganized family and inconsistent medical care. ${ }^{13}$ These characteristics are now considered as a sign of neglect in pediatric care. A common sign of parental neglect is a dirty child and studies have shown that a neglected (dirty) child suffered higher odds for obesity than average groomed children. ${ }^{25}$ Clinical evidence of parental neglect is reflected by the way they groom their children that includes clothing, tidy hair (absence of dandruff and lice), dried nasal discharge, dirty nails, body odor, oral hygiene and their living environment. Care is largely affected by parental dependence on alcohol and drugs. Parental substance abuse (alcohol, drugs) also amounts to care neglect. ${ }^{14}$ Besides parental smoking, teen pregnancy ${ }^{26}$ and suicidal thinking/intention ${ }^{24,27}$ in children also amount to extreme care neglect. Neglect 
and sexual abuse have been associated with an increased risk of obesity in adulthood. ${ }^{26,28}$ In a coalesced data from various studies by Levine, ${ }^{29}$ it was found that about one-third of the female obese patients seeking treatment specified history with sexual abuse. The relation between the 2 has been explained on the basis of various mechanisms that include a higher prevalence of mood disorders, depression, abuse survivorship and obesity as an adaptation to being a victim of abuse. ${ }^{29}$ Begging by children with consent of parents or alongside parents is common in the middle east and south east Asian countries, which surmounts to care neglect.

Medical neglect. Regular medical care is essential for a child who is growing with each day. Parents show neglectful behavior if they fail to take the child for routine regular check ups, do not follow physician's instructions, do not take child to hospital in case of an emergency, and do not give medications. ${ }^{30} \mathrm{~A}$ child who refuses to eat fruits, should be provided with alternate supplements of foods that are rich in vitamins. Nursing bottle dental decay or rampant caries in children is a form or extreme medical neglect by parents.

Supervisory neglect. It is one of the most recorded forms of neglect and is described as the failure of a primary caregiver to plan or have an awareness of a child's activity or engaged in at risk behaviors. A caregiver who does not watch his child close enough, leaving a child without a caretaker or with an unsuitable caretaker are some basic examples. Basic needs neglect is applicable when the caregiver is incapable to afford adequate food, required clothing or shelter. ${ }^{18}$ Supervisory neglect by parents or a caregiver increases alcohol consumption in both male and female adults. ${ }^{31}$ A significant component of parental supervision is the use of corporal disciplining (thrashing/beating) by parents in most of the cultures. Abusing the child like corporal punishment has been established to encompass significant association with negative outcomes like internalizing and externalizing behaviors and low cognitive performance, ${ }^{32}$ while its relation to eating disorders has also been reported. ${ }^{33}$ Children are sensitive to violence, even if the violence is not upon them. Childhood violence victims of African American urban youth developed obesity during adulthood. ${ }^{34}$ Previous studies $^{9,15}$ on interpersonal violence between partners, in the community or from peers have found a link between obesity and interpersonal violence (minimum one form) in childhood.

Feeding behavior. Feeding is an essential component of learning behavior and parents play the most important role in developing such behavior. Both supervision and care are involved in imparting such behavior. Feeding habits learned during childhood are practiced during adulthood and then transferred to the next generation. Mothers should not encourage children to empty feeding bottles with formula food as such early experiences may lead to non development of control over food intake. The context in relation to food being given to the child can be either positive or negative. Parents who work daily outside, do not eat breakfast daily with their preschool children, thus encouraging children to eat outside. The importance of having breakfast is known to all cultures. If and when parents do not eat breakfast, children are more likely to miss the breakfast too. Breakfast skipping by both parents increases the child risk (18 to $116 \%$ ) to become overweight/obese. ${ }^{35}$ Well being of children is dependent on daily interactions with parents, participation in extracurricular activities, and parents' feelings towards their children. Among the various factors that influence a child to develop healthy eating habits are meals with family members, the choice of food available at home, home cooked food and variation in cooking. Eating outside results in the consumption of more fat and calories by children while also reducing less intake of fiber rich food. ${ }^{36}$ Even a single meal per week in a fast food has revealed to result in an increase of BMI by $0.8 \mathrm{~kg} / \mathrm{m}^{2} \cdot{ }^{37}$ Eating in a restaurant is also accompanied by more than usual sit down process which itself leads to increase in BMI. ${ }^{37}$ Parents who make sure that their children eat breakfast, reduce the risk of children eating outside when and if the child feels hungry. Parents have the responsibility of developing child's self regulation ability. Studies on self regulation of the food by children have demonstrated that parenting practices of providing food based on environmental cues like time of dinner rather than the hunger itself affect child's self regulation ability. ${ }^{38,39}$ As early as 3-5 years of age, children have shown little evidence of ability to adjust food intake in response to the altered energy density of food thus leading to increased amounts of intake. ${ }^{40}$ Control of feeding practice has been credited to the findings that suggest that fathers may play a role in the control of feeding practices since daughters whose fathers were stricter on control of food had a higher percent of fat. While studying the feeding styles in obese subjects 4 different types of feeding styles were associated with the development of obesity, namely emotional feeding, instrumental feeding, encouragement and controlled feeding. ${ }^{41}$ These 4 feeding styles make the child a poor regulator of his/her own energy intake.

Body activity (social and physical). Social activity initiates competitiveness among children as well as adults. Inverse relationship between physical activity 
is a well known fact and has scientific validation too. Physical activity, social and physical context is diminishing. Lack of outdoor activity ( $\leq 2$ hours on non-school days) increases the risk for a child being overweight. ${ }^{42}$ Active parents in term of physical activity tend to produce active children. ${ }^{43}$ Children whose mothers are practically inactive seem to be at a higher risk for developing obesity. ${ }^{44}$ Rivas in $2017,{ }^{45}$ correlated parental nature relatedness to the BMI values and concluded that parents who identified nature do not allow their children to engage in unhealthful activities. The study also indicates that food choices are more thoughtful in individuals who spend more time in active nature. The digital insurgency and modern technology are replacing the real nature, and advances in immersive virtual reality games are reducing physical activity in children. ${ }^{46}$ Although WHO recommends not more than one hour (or even less) of screen time per day, ${ }^{47}$ studies have reported the excess use of screens (Kaiser family foundation) in children aged 8-10 years who were spending nearly 8 hours and teenagers more than 11 hours per day on screens. When children have free time they should develop the habit of spending such time in physical activity.

There is a significant association of familial influence on leisure time exercise participation. The maximum heritability found was that for the degree of inactivity while on the contrary studies in accelerometry suggest heritability of physical activity to be between the range of $51 \%$ to $56 \% .{ }^{48}$ The personality of an individual in a family has been proven to be a highly heritable factor. ${ }^{49}$ While there is a decline in physical activities with age across the life span of an individual, ${ }^{50}$ the physical activity patterns that are developed during childhood may continue into adulthood and are important for tackling obesity. Sedentary lifestyle has various components that are interlinked to each other. Like not performing physical activity may lead to watching television (TV), which, when carried out in excess deprives sleeping time. ${ }^{51}$ Parents have the responsibility to limit preschoolers TV and video viewing and keep TV out of their bedrooms as it was found that children skip family meals while watching the TV in their individual rooms. ${ }^{52}$ It must be understood that somatic activity has a protective effect for the development of childhood obesity as it increases energy expenditure and regulates eating behavior via endocrine mediators. ${ }^{53}$ Besides, acute exercise reduces obese adolescents energy intake. $^{54}$

Parenting and parenting style. Parental basic literacy and numeracy skills have been found to be low. ${ }^{55}$ These have significance in formula feeding and selecting the food according to the nutritional value present on the labels. Parents have also demonstrated failure to recognize their children being overweight, which is a big challenge in tackling obesity. ${ }^{56}$ Parents who do not identify overweight children tend to continue their feeding style and habits according to their preference, which later transforms into obesity. Mothers are responsible to provide a favorable intrauterine environment as it can increase future risk of developing adult metabolic abnormalities including obesity. ${ }^{57}$ Mothers are a role model for every child irrespective of gender. Poor role models, especially the mother, significantly increase child's obesity risk. ${ }^{58}$ Parental smoking, especially that of the mother (during pregnancy and after birth) risks development of obesity and also presents mothers as a poor role model. ${ }^{59}$ While its an established fact that mothers longer working hours is associated as a higher risk for child becoming overweight, recent study has also suggested that fathers working hours (55 hours/week) strengthened the effect of mothers, ${ }^{60}$ both working parents decrease the potential time given to the children for health promoting activities. Breast feeding is directly related to obesity risk and a clear dose response effect has been identified for its duration. ${ }^{61}$ The breastmilk has flavor compounds (garlic, carrot, vanilla, tobacco) which the child is exposed when in the womb (amniotic fluid). Longer breastfeeding has also been associated with greater intake of healthy diet in young children.

Investigations into various parenting styles associated with obesity suggests that children of authoritarian parents (strict disciplinarians) have a higher hazard while authoritative (respectful of children's opinions, but maintain clear boundaries) parenting was associated with low risk. ${ }^{62}$ Cultural diversifications of parenting from traditional to modern, lays emphasis that parents become non interfering with children's activities even in case of significant misbehavior. Such emphasis has diluted parental role in their responsibility of child rearing. ${ }^{63}$ Lower obesity rate in children exists in those who live with grandparents. ${ }^{64}$ This is because of the traditional parenting wherein the parent is responsible for the child's behavior and activities including the food he is provided with. ${ }^{65}$ The parenting style (authoritative) produces a straight effect on family feeding practices which cumulates an opposite effect of child's dietary habits.

Such parents posses nutritional knowledge, positive attitude and high control while demonstrating a highly responsible behavior. Both authoritarian and permissive styles have been reported with high prevalence of overweight children. ${ }^{62,63}$ Authoritative parenting leads to increased consumption of fruits, juices, and vegetables 
by children while they also consumed less junk food. ${ }^{66}$ Studies have also shown that feeding practices like frequent feeding, large portion feeds, offering preferred food, offering food as a first response, coercing a child to eat when food is available are associated with high prevalence of obesity. The social influences of parents have also been studied and parents must understand that food advertisements are aimed exclusively at children right from his birth to being an adult. ${ }^{67}$ During infancy, parents are targeted to use formula foods, with preschool and school age fast foods and soft drinks become routine food while as young adults unhealthy food is associated with enjoyment and parties. ${ }^{67}$

Mechanism of action. Parental neglect is bound to develop psychological states in their children, that affect energy balance through altered behavior, hormonal balance which in turn leads to obesity. Physiologically, the possible pathway that links psychological states and obesity involves the hypothalamus-pituitaryadrenocortical system, which responds to stressful situations by altering hormones (cortisol). ${ }^{68}$ Increased cortisol levels do promote the activity of lipid accumulating enzymes in visceral fat. Neglect induces distress, which may elicit a stress response in the hypothalamus, pituitary adrenal and sympathetic nervous system. Stress may induce overeating or stress induced eating that is abnormal in nature. ${ }^{69}$ Stress hormones bring changes in the metabolic system and also changes in how the brain structure regulates energy.

Implications among Saudipopulation. The Kingdom has had a history of under reporting the problem of child neglect. Between 1990 to 2000, only 11 incidents were conveyed in the form of case studies. But by 2000, the government had recognized the problem which led to installation of child protection centers in major hospitals. ${ }^{70}$ According to the Saudi national family safety registry (NFSR) report of 38 hospital based child safety centers, 292 cases ( $43 \%$ neglect) of child ill treatment were registered in $2010^{71}$ which rose to 895 cases $(31 \%$ neglect) in $2011 .^{72}$ Within a space of 3 years between 2010 to 2012, a total no of 1,450 instances of child abuse were reported (only 21 centers) out of which 511 cases $(35 \%)$ were classified as neglect. Males were reported to suffer more from neglect than females. The reasons for most of the centers inability to report included lack of recognition skills, non awareness of referral and in compliance with registry case reporting guidelines. No further reports of this kind have been given by the government since 2012. Meanwhile, in 2016, Al Eissa et $\mathrm{al}^{73}$ conducted a study $(\mathrm{n}=16,939)$ students aged between 15-19 years across 5 main regions of KSA and found that $53 \%$ of participants had experienced neglect (girls more than boys). Coincidentally, the problem of corpulence has hit the Kingdom for many years now. The problem is serious since studies have reported approximately $35 \%$ to $40 \%$ of the adult population to be obese, according to a national survey reported in 2013, ${ }^{19}$ while independent studies have shown it to be in the range of staggering $66 \%$ to $75 \%$ of adults to be either overweight or obese. ${ }^{20}$ Although the relation between parent neglect and obesity have been established elsewhere, there is a conspicuous absence of such studies in KSA. Saudi Arabia has its own set of social determinants due to tradition, cultural, geographical, historical, and religious factors that could be a possible link to the growing rates of the obesity in KSA. Some of the social determinants which have been previously reported studies are listed in Table 1 . With a known history of child maltreatment and the current epidemic of obesity the role of parent neglect during childhood is worth investigating as it could be a sign of predictors of adulthood obesity in the population.

In conclusion, although complex, the relation between parental neglect in feeding and establishing a sense of competitive social activity within their children, demands scientific investigation among the Saudi population since the geographical location and cultural restrictions promotes staying indoors. Existing scientific evidence shows the significance of parental role

Table 1 - Social determinants in Saudi Arabia that are linked to obesity.

\begin{tabular}{l}
\hline Social determinants in Saudi Arabia \\
\hline Tribal attitude that considers obesity (plumpness) to signify affluence and \\
beauty. \\
Multiple pregnancies with short intervals \\
Postpartum practices of eating, increased traditional food containing lots \\
of oil and animal fat \\
Consanguineous marriages are common \\
Depending on house maid \\
Cultural norms of self image where mild to moderately obese individuals \\
consider themselves as normal \\
Lack of exercise routines and facilities in schools for women \\
Economic prosperity and its concomitant drivers of obesity \\
Parental neglect in terms of feeding and social activity \\
No preference for traditional foods that were high in fiber \\
Very high television ownership \\
Under-reported, but high prevalence of child abuse and neglect
\end{tabular}


as a model in the deterrence of overweight and obesity. Since parental neglect is complex, it also provides the scientific community a sea of variables that are worth investigating.

Acknowledgment. This review article was a part of a descriptive study that was supported by a grant fund from the 7 th research program of Deanship of Scientific Research, College of Dentistry, Jazan University, Jazan, Saudi Arabia. Authors would also like to acknowledge Scribendi for language editing.

\section{References}

1. Wolfenden L, Ezzati M, Larijani B, Dietz W. The challenge for global health systems in preventing and managing obesity. Obesity Reviews 2019; 20: 185-193.

2. Ford ND, Patel SA, Narayan KMV. Obesity in low and middleincome countries: burden, drivers, and emerging challenges. Annu Rev Public Health 2017; 38: 145-164.

3. Kent S, Fusco F, Gray A, Jebb SA, Cairns BJ, Mihaylova B. Body mass index and healthcare costs: a systematic literature review of individual participant data studies. Obesity Reviews 2017; 18: 869-879.

4. Breslow L. Public health aspects of weight control. Am J Pub Health 1952; 42: 1116-1118.

5. Yanovski J. Trends in underweight and obesity - scale of the problem. Nat Rev Endocrinol 2018; 14: 5-6.

6. Silventoinen K, Jelenkovic A, Sund R, Hur YM, Yokoyama Y, Honda C, et al. Genetic and environmental effects on body mass index from infancy to the onset of adulthood: an individualbased pooled analysis of 45 twin cohorts participating in the COllaborative project of development of anthropometrical measures in twins (CODATwins) study. The American Journal of Clinical Nutrition 2016; 104: 371-379.

7. Goldfeder RL, Wall DP, Khoury MJ, Ioannidis JPA, Ashley EA. Human genome sequencing at population scale: a primer on high-throughput DNA sequencing and analysis. $\mathrm{Am} \mathrm{J}$ Epidemiol 2017; 186: 1000-1009.

8. Liu AL, Xie HJ, Xie HY, Liu J, Yin J, Hu JS et al. Association between fat mass and obesity associated (FTO) gene rs9939609 A/T polymorphism and polycystic ovary syndrome: a systematic review and meta-analysis. BMC Med Genet 2017; 18: 89.

9. Garrahan SM, Eichner AW. Tipping the Scale: A place for childhood obesity in the evolving legal framework of child abuse and neglect. Yale J Health Policy Law and Ethics 2012; 12: 336-370.

10. Mannan M, Mamun A, Doi S, Clavarino A. Is there a bidirectional relationship between depression and obesity among adult men and women? Systematic review and bias-adjusted meta analysis. Asian J Psychiatr 2016; 21: 51-66.

11. Widom CS, Czaja SJ, Kozakowski SS, Chauhan P. Does adult attachment style mediate the relationship between childhood maltreatment and mental and physical health outcomes? Child Abuse \& Neglect 2018; 76: 533-545.

12. Harper NS. Neglect: failure to thrive and obesity. Pediatr Clin North Am 2014; 61: 937-957.
13. Mason SM, Bryn Austin S, Bakalar JL, Boynton-Jarrett R, Field AE, Gooding HC et al. Child maltreatment's heavy toll: the need for trauma-informed obesity prevention. Am J Prev Med 2016; 50: 646-649.

14. Wolitzky-Taylor K, Sewart A, Vrshek-Schallhorn S, Zinbarg $\mathrm{R}$, Mineka S, Hammen $\mathrm{C}$ et al. The effects of childhood and adolescent adversity on substance use disorders and poor health in early adulthood. J Youth Adolesc 2017; 46: 15-27.

15. Lorber MF, White-Ajmani ML, Dixon D, Slep AMS. Heyman RE. The relations of child adiposity with parent-to-child and parent-to-parent hostility. Psychology \& Health 2017; 32: 1386-1406.

16. O’Neill A, Beck K, Chae D, Dyer T, He X, Lee S. The pathway from childhood maltreatment to adulthood obesity: the role of mediation by adolescent depressive symptoms and BMI. Journal of Adolescence 2018; 67: 22-30.

17. Varness T, Allen DB, Carrel AL, Fost N. Childhood obesity and medical neglect. Pediatrics 2009; 123: 399-406.

18. Yang M, Maguire JK. Predictors of basic needs and supervisory neglect: Evidence from the Illinois families study. Children and Youth Services Review 2016; 67: 20-26.

19. AbdulRahim HF, Sibal A, Khader Y, Hwalla N, Fadhil L, Alsiyabi $\mathrm{H}$, et al. Health in the arab world: A view from within 2 noncommunicable diseases in the arab world. Lancet 2014; 383: 356-367.

20. Alhaqwi A, Alnasir M, Ahmed N, Masaudi E, Alotaibi S, Bashir $\mathrm{H}$. Obesity and overweight in a major family practice center, central region, Saudi Arabia. Saudi J Obes 2015; 3: 12-17.

21. Paez A. Gray literature: An important resource in systematic reviews. J Evid Based Med 2017; 10: 233-240.

22. Al-Eissa MA, AlBuhairan FS, Qayad M, Saleheen H, Runyan $\mathrm{D}$, Almuneef M. Determining child maltreatment incidence in Saudi Arabia using the ICAST-CH: A pilot study. Child Abuse Negl 2015; 42: 174-182.

23. Mahmoud SS, Khamis KA, Mania KM, Darbashi SA, Doshi YA, Hefdhi AM, Mohammed RT. Prevalence and predictors of khat chewing among students of jazan university, Jazan, Kingdom of Saudi Arabia. Int J Prevent Public Health Sci 2017; 2: 1-6.

24. Scott D. Reporting fatal neglect in child death review. Trauma Violence Abuse 2018; 21: 382-392.

25. Johnson WF, Huelsnitz CO, Carlson EA, Roisman GI, Englund MM, Miller GE, et al. Childhood abuse and neglect and physical health at midlife: Prospective, longitudinal evidence. Dev Psychopathol 2017; 29: 1935-1946.

26. Sharley V, Ananias J, Rees A, Leonard E. Child Neglect in Namibia: Emerging Themes and Future Directions. Br J Soc Work 2019; 49: 983-1002.

27. Kwok SYCL, Gu M. Childhood neglect and adolescent suicidal ideation: A moderated mediation model of hope and depression. Prev Sci 2019; 20: 632-642.

28. Ramirez JC, Milan S. Childhood sexual abuse moderates the relationship between obesity and mental health in low-income women. Child Maltreat 2016; 21: 85-89.

29. Levine JA, McCrady-Spitzer SK, Bighorse W. Obesity and sexual abuse in American Indians and Alaska natives. $J$ Obes Weight Loss Ther 2016; 6: e119.

30. Gray J, Cadieux A, Sweeney B, Beck AR, Edgar S, Eneli I et al. Medical neglect and pediatric obesity: Insights from tertiary care obesity treatment programs. Children's Health Care 2017; 46: 246-264. 
31. Snyder SM, Merritt DH. The effect of childhood supervisory neglect on emerging adults' drinking. Subst Use Misuse 2016; 51: 1-14.

32. Pinquart M. Associations of parenting dimensions and styles with externalizing problems of children and adolescents: An updated meta-analysis. Developmental Psychology 2017; 53: 873-932.

33. Afifi TO, Sareen J, Fortier J, Taillieu T, Turner S, Cheung K, et al. Child maltreatment and eating disorders among men and women in adulthood: Results from a nationally representative United States sample. Int J Eat Disord 2017; 50: 1281- 1296.

34. Assari S, Caldwell CH, Abelson JL, Zimmerman M. Violence victimization predicts body mass index one decade later among an urban sample of African American young adults: Sex as a moderator and dehydroepiandrosterone as a mediator. J Urban Health 2019; 96: 632-643.

35. Okada C, Tabuchi T, Iso H. Association between skipping breakfast in parents and children and childhood overweight/ obesity among children: a nationwide 10.5 -year prospective study in Japan. Int J Obes 2018; 42: 1724-1732.

36. Bhutani S, Schoeller DA, Walsh MC, McWilliams C. Frequency of eating out at both fast-food and sit-down restaurants was associated with high body mass index in non-large metropolitan communities in Midwest. Am J Health Promot 2018; 32: 75-83.

37. Smethers AD, Roe LS, Sanchez CE,.Zuraikat FM, Keller KL, Rolls BJ. Both increases and decreases in energy density lead to sustained changes in preschool children's energy intake over 5 days. Physiol Behav 2019; 204: 210-218.

38. Potter C, Ferriday D, Griggs RL, Hamilton-Shield JP, Rogers PJ, Brunstrom JM. Parental beliefs about portion size, not children's own beliefs, predict child BMI. Pediatr Obes 2018; 13: 232-238.

39. Kairey L, Matvienko-Sikar K, Kelly C, McKinley MC, O'Connor EM, Kearney PM et al. Plating up appropriate portion sizes for children: a systematic review of parental food and beverage portioning practices. Obes Rev 2018; 19: 1667-1678.

40. Saltzman JA, Pineros-Leano M, Liechty JM, Bost KK, Fiese BH, STRONG Kids Team. Eating, feeding, and feeling: emotional responsiveness mediates longitudinal associations between maternal binge eating, feeding practices, and child weight. Int J Behav Nutr Phys Act 2016; 13: 89.

41. Steinsbekk S, Barker ED, Llewellyn C, Fildes A, Wichstrøm L. Emotional feeding and emotional eating: reciprocal processes and the influence of negative affectivity. Child Dev 2018; 89: 1234-1246.

42. Zhang J, Zhang Y, Jiang Y, Sun W, Zhu Q, Ip P, et al. Effect of sleep duration, diet, and physical activity on obesity and overweight elementary school students in Shanghai. J Sch Health 2018; 88: 112-121.

43. Lin X, Eaton CB, Manson JE, Simin L. The genetics of physical activity. Curr Cardiol Rep 2017; 19: 119.

44. Muntaner-Mas A, Vidal-Conti J, Cantallops J, Borràs PA, Palou P. Obesity and physical activity patterns among Balearic Islands children and adolescents: a cross-sectional study. J Sport Exerc Psychol 2017; 12: 333-348.

45. Rivas E. The relationship between parental nature relatedness and overweight/obesity in elementary school children. Master's thesis, Harvard Extension School [cited 2017]. Available from: http://nrs.harvard.edu/urn-3:HUL.InstRepos:33813398
46. Frumkin H, Bratman GN, Breslow SJ, Cochran B, Kahn PH Jr, Lawler JJ, et al. Nature contact and human health: a research agenda. Environ Health Perspect 2017; 125: 075001.

47. Council on communications and media. Media and young minds. Pediatrics 2016; 138: e20162591.

48. Zhang X, Speakman JR. Genetic factors associated with human physical activity: Are your genes too tight to prevent you exercising? Endocrinology 2019; 160: 840-852.

49. Wilson KE, Das BM, Evans EM and Dishman RK. Personality correlates of physical activity in college women. Med Sci Sports Exerc 2015; 47: 1691-1697.

50. Van Hecke L, Loyen A, Verloigne M, Van der Ploeg HP, Lakerveld J, Brug J, et al. Variation in population levels of physical activity in European children and adolescents according to cross-European studies: a systematic literature review within DEDIPAC. Int J Behav Nutr Phys Act 2016; 13: 70.

51. Przybylski AK, Weinstein N. Digital screen time limits and young children's psychological well-being: Evidence from a population-based study. Child Dev 2019; 90: e56-e65.

52. Gentile DA, Berch ON, Choo H, Khoo A, Walsh DA. Bedroom media: One risk factor for development. Dev Psychol 2017; 53 : 2340-2355.

53. Slutsky N, Vatarescu M, Haim Y, Goldstein N, Kirshtein B, Harman-Boehm I et al. Decreased adiponectin links elevated adipose tissue autophagy with adipocyte endocrine dysfunction in obesity. Int J Obes 2016; 40: 912-920.

54. Fearnbach SN, Silvert L, Pereira B, Boirie Y, Duclos M, Keller KL et al. Reduced neural responses to food cues might contribute to the anorexigenic effect of acute exercise observed in obese but not lean adolescents. Nutr Res 2017; 44: 76-84.

55. Yin HS, Sanders LM, Rothman RL, Shustak R, Eden SK, Shintani A et al. Parent health literacy and "obesogenic" feeding and physical activity related infant care behaviours. J Pediatr 2014; 164: 577e1-583e1.

56. Queally M, Doherty E, Matvienko-Sikar K, Toomey E, Cullinan J, Harrington JM, et al. Do mothers accurately identify their child's overweight/obesity status during early childhood? Evidence from a nationally representative cohort study. Int J Behav Nutr Phys Act 2018; 15: 56.

57. Elshenawy S, Simmons R. Maternal obesity and prenatal programming. Mol Cell Endocrinol 2016; 435: 2-6.

58. Martin-Biggers J, Quick V, Byrd-Bredbenner C. Development of an obesity risk score for mothers of young children. The FASEB Journal 2017; 31: 960.3-960.3.

59. Magriplis E, Farajian P, Panagiotakos DB, Risvas G, Zampelas A. Maternal smoking and risk of obesity in school children: Investigating early life theory from the GRECO study. Prev Med Rep 2017; 8: 177-182.

60. Li J, Kaiser T, Pollmann-Schult M, Strazdins L. Long work hours of mothers and fathers are linked to increased risk for overweight and obesity among preschool children: longitudinal evidence from Germany. J Epidemiol Community Health 2019; 73: 723-729.

61. Ventura AK. Does breastfeeding shape food preferences links to obesity. Ann Nutr Metab 2017; 70 (Suppl 3): 8-15.

62. Sokol RL, Qin B, Poti JM. Parenting styles and body mass index: a systematic review of prospective studies among children. Obesity Reviews 2017; 18: 281-292.

63. Melis Yavuz H, Selcuk B. Predictors of obesity and overweight in preschoolers: the role of parenting styles and feeding practices. Appetite 2018; 120: 491-499. 
64. Freeland-Graves J, Jacobvitz DB, Sachdeva P. Role of grandparents in childhood obesity during first two years of life. J Nutrition Health Food Sci 2018; 6: 1-11.

65. Li B, Adab P, Cheng KK. The role of grandparents in childhood obesity in China - evidence from a mixed methods study. Int J Behav Nutr Phys Act 2015; 12: 91.

66. Langer SL, Seburg E, Jaka MM, Sherwood NE, Levy RL. Predicting dietary intake among children classified as overweight or at risk for overweight: independent and interactive effects of parenting practices and styles. Appetite 2017; 110: 72-79.

67. Horgen KB, Choate M, Brownell KD. Television food advertising: Targeting children in a toxic environment. In: Singer DG, Singer JL, editors. Handbook of Children and the Media. Thousand Oaks (CA): Sage; 2001. p. 447-461.

68. Hewagalamulage S, Lee TK, Clarke IJ, Henry BA. Stress, cortisol, and obesity: a role for cortisol responsiveness in identifying individuals prone to obesity. Domest Anim Endocrinol 2016; 56: S112-S120.
69. Ebrahimi F, Urwyler SA, Schuetz P, Mueller B, Bernasconi L, Neyer P et al. Effects of interleukin-1 antagonism on cortisol levels in individuals with obesity: a randomized clinical trial. Endocr Connect 2019; 8: 701-708.

70. Alsehaimi A, Alanazi A. The extent of negligence of children in Saudi Arabia: A literature review. J Child Dev Disord 2017; 3: 3.

71. National Family Safety Registry Committee. The National Family Safety Registry Report Annual Report 2010. KSA: National Family Safety Registry Committee; 2010. p.1-35.

72. National Family Safety Registry Committee. The National Family Safety Registry Report Annual Report 2012. KSA: National Family Safety Registry Committee; 2012.

73. Al-Eissa MA, Saleheen HN, AlMadani S, AlBuhairan FS, Weber A, Fluke JD, et al. Determining prevalence of maltreatment among children in the Kingdom of Saudi Arabia. Child Care Health Dev 2016; 42: 565-571. 